\title{
EVALUATION OF OCCURRENCE OF H. PYLORI INFECTION AND EFFICACY OF ERADICATION THERAPY IN PEPTIC ULCER DISEASE
}

\author{
Prashant S. Dorkar1, Prakash Gurav², Santosh Dalviं, Prachi Dharmadhikari ${ }^{4}$, Anand H. Devraj ${ }^{5}$
}

${ }^{1}$ Assistant Professor, Department of General Surgery, Government Medical College and Hospital, Miraj, Sangli.

2Professor, Department of General Surgery, Government Medical College and Hospital, Miraj, Sangli.

${ }^{3}$ Associate Professor, Department of General Surgery, Government Medical College and Hospital, Miraj, Sangli.

${ }^{4}$ Resident Doctor (Postgraduate Student), Department of General Surgery, Government Medical College and Hospital, Miraj, Sangli.

${ }^{5}$ Resident Doctor (Postgraduate Student), Department of General Surgery, Government Medical College and Hospital, Miraj, Sangli.

\section{ABSTRACT}

\section{BACKGROUND}

Acid Peptic disease is one of the most common condition seen in routine practice. Symptoms may vary from vague abdominal pain and burning sensation to massive upper GI bleeding to Ulcer perforation. The endoscopic appearance of an ulcer provides important prognostic information. Endoscopic treatment in patients with high-risk stigmata results in improved outcomes. H. Pylori eradication therapy also improves quality of life.

\section{MATERIALS AND METHODS}

This is a retrospective observational study of 250 patients who underwent upper GI endoscopy for various reasons in GMCH, Miraj from April 2016 to Feb. 2017. Out of 250 cases, 101 patients who had peptic ulcers were studied. Detailed History, Patients' symptoms and signs and recurrence rate were analysed. All post-endoscopy data and post-endoscopy management plans were analysed.

\section{RESULTS}

In this study, out of 250 (182 males, 68 females) patients who underwent upper GI scopy, it was observed that out of 250 cases, 101 patients (72 males and 29 females) had peptic ulcers. Out of 101 cases, 73 (72.27\%) patients (52 males and 21 females) were positive and $28(27.72 \%)$ were negative (20 males and 8 females) for H. pylori infection on rapid urease test. There was no significant association of $\mathrm{H}$. pylori infection in relation to gender $(\mathrm{P}=0.984)$. Eradication therapy given for 14 days to all 73 positive patients. After completion of eradication therapy, repeat endoscopy was done after 4 weeks and found that out of 73 positive cases, 65 (89.041\%) patients who were kept on maintenance dose of PPI for 3 weeks were cured. Those 8 patients who were not cured were allowed to continue eradication therapy for 14 more days and then on PPI for 3 weeks. After completion of this treatment, they were found negative for $\mathrm{H}$. pylori infection on repeat endoscopy.

\section{CONCLUSION}

Acid peptic disease is one of the most common condition encountered in routine practice. There was no statistical significance for occurrence of $\mathrm{H}$. pylori infection in relation to gender $(\mathrm{p}=0.984)$. Majority of cases can be managed with medical treatment. There is no recurrence if peptic ulcer disease is managed with eradication therapy along with elimination of all causative factors. Surgical treatment is needed for those who present with complications like intractable pain, massive upper GI bleeding, ulcer perforation, etc. For those who were positive for H. Pylori, eradication therapy (Omeprazole/Pantoprazole, Amoxicillin/Clarithromycin, Metronidazole/Ornidazole) with or without Bismuth subcitrate is the best treatment.

\section{KEYWORDS}

H. Pylori, Peptic Ulcer Disease, Forrest Classification, Rapid Urease Test.

HOW TO CITE THIS ARTICLE: Dorkar PS, Gurav P, Dalvi S, et al. Evaluation of occurrence of H. Pylori infection and efficacy of eradication therapy in peptic ulcer disease. J. Evolution Med. Dent. Sci. 2017;6(80):5661-5663, DOI: 10.14260/jemds/2017/1227

\section{BACKGROUND}

Peptic ulcer is defined as a circumscribed ulceration of the gastrointestinal mucosa occurring in areas exposed to acid and pepsin and most often caused by Helicobacter pylori infection. (Uphold \& Graham, 2003). Common sites for peptic ulcers are the first part of the duodenum and lesser curvature

'Financial or Other Competing Interest': None.

Submission 26-08-2017, Peer Review 24-09-2017,

Acceptance 30-09-2017, Published 05-10-2017.

Corresponding Author:

Dr. Prashant Dorkar,

Dorkar Hopsital,

Near Anand Nursing Home,

Sangli Road, Miraj, Sangli,

Maharashtra.

E-mail: prashantdorkar@yahoo.in

DOI: $10.14260 /$ jemds $/ 2017 / 1227$ of the stomach, but they can occur in sites which contain ectopic gastric mucosa, e.g. Meckel's diverticulum, stoma sites following gastric surgeries. Most common cause for peptic ulcer is H. pylori infection, so eradication of $\mathrm{H}$. pylori is very essential. Duodenal ulcers are more common than gastric ulcers which can be differentiated clinically.

$\mathrm{H}$. pylori is associated with various diseases - many benign, premalignant and malignant lesions of digestive system including chronic gastritis, peptic ulcers, atrophic gastritis, intestinal metaplasia, gastric adenoma, gastric hyperplastic polyp, adenocarcinoma, lymphoma, etc. ${ }^{1} \mathrm{H}$. Pylori infection is acquired early in life in the Indian population. The H. pylori infection has a high morbidity rate, but a low mortality rate and is curable with antimicrobial therapy. ${ }^{2}$ Successful treatment and eradication of $\mathrm{H}$. pylori cures the ulcer disease. As the initial infection with this bacterium mainly occurs during childhood, re-infection in 
adults is very rare. ${ }^{3}$ The lower $\mathrm{H}$. pylori prevalence among female gastric ulcer patients may be due to the higher prevalence of NSAID use. ${ }^{4} \mathrm{H}$. pylori infection can be detected by invasive or non-invasive method. Non-invasive test includes serology and carbon-labelled urea breath test. The invasive test includes the rapid urease test, histological examination and culture. ${ }^{1}$

In this study, we used Rapid urease test which is more convenient and result comes quickly. Rapid urease test is one of the invasive test, based on use of endoscopic biopsy specimen. The principle is that abundant urease enzyme produced by $\mathrm{H}$. pylori hydrolyses urea to ammonia. The consequent rise in the $\mathrm{pH}$ of the medium is detected by phenol red indicator. ${ }^{5}$ Biopsy rapid urease testing is the most simple and rapid method for identifying $H$. pylori infection in endoscopic practice and also there are very less chances of false positive reaction. ${ }^{6}$ Some studies suggest quadruple therapy for resistant bacteria that includes bismuth subcitrate in addition to antacid and other antimicrobials. ${ }^{7}$

The Forrest classification is most widely used to classify the endoscopic appearance of bleeding peptic ulcers. It is used to predict the risk of re-bleeding and mortality and is known to have a stronger association with gastric ulcers compared with duodenal ulcers. The Forrest classification classifies ulcers with a spurting haemorrhage (Forrest Ia), oozing haemorrhage (Forrest Ib), a visible vessel (Forrest IIa), an adherent clot (Forrest IIb), haematin on the ulcer base (Forrest IIc), and a clean ulcer base (Forrest III). ${ }^{8}$

Symptoms are pain, "gnawing", "aching" or "burning". Duodenal ulcers occur 1-3 hours after a meal and may awaken patient from sleep. Pain is relieved by food, antacids, or vomiting. In gastric ulcers, food may exacerbate the pain while vomiting relieves it. Nausea, vomiting, belching, dyspepsia, bloating, chest discomfort, anorexia, haematemesis, \&/or melaena may also occur. Nausea, vomiting and weight loss are more common with gastric ulcers.

Symptoms of acid peptic disease are primarily due to imbalance between protective and damaging factors of gastric mucosa, Helicobacter pylori, Smoking/Alcohol, Spicy food Duodenogastric bile reflux, Gastric stasis, abnormal acid secretion, pepsin secretion (e.g. Gastrinoma), NSAIDS, Steroids, Lower socioeconomic group.

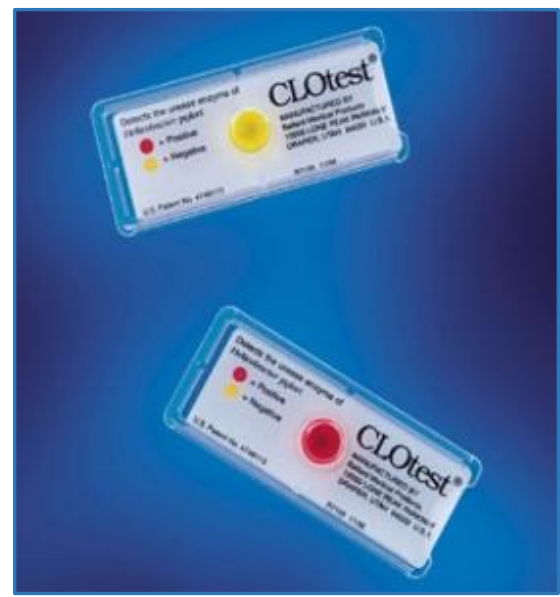

Picture 1. Rapid Urease Test Kit

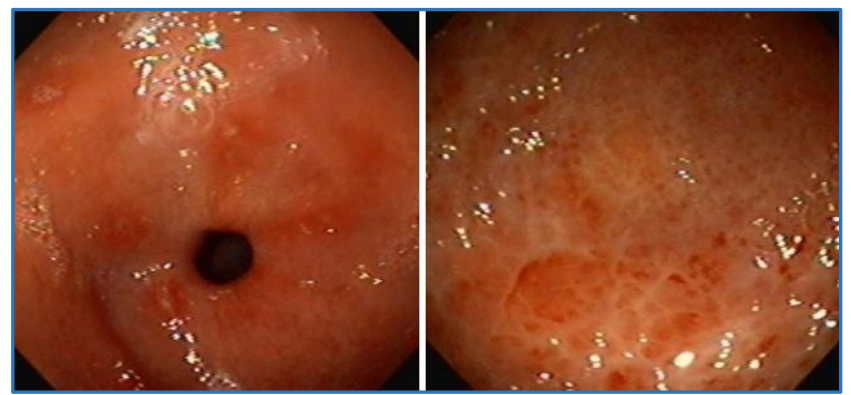

Picture 2 \& 3. Forrest Class IIc Ulcer

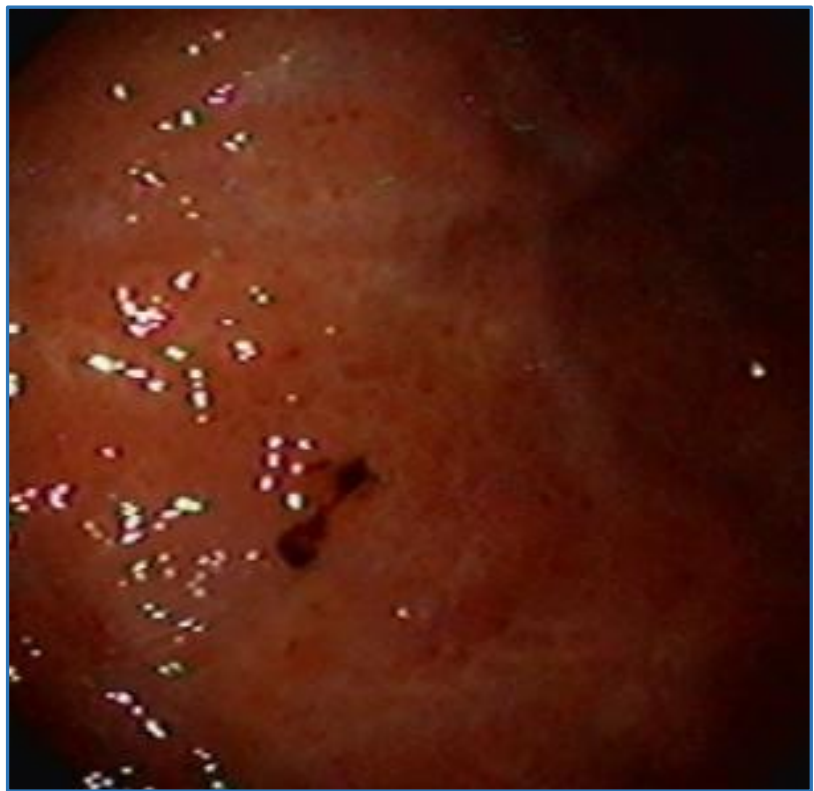

Picture 4. Forrest Class III Ulcer

\section{MATERIALS AND METHODS}

This is a retrospective observational study of 250 patients who underwent upper GI endoscopy for various reasons in GMCH, Miraj from April 2016 to Feb. 2017. Out of 250 cases, 101 patients who had peptic ulcers were studied. Detailed History, Patients' symptoms and signs and recurrence rate were analysed. All Post-endoscopy data and post-endoscopy management plans were analysed. Chi square test and percentages were used to analyse data.

\section{Minitab Software used to Analyse Data- Patient Selection Criteria Inclusion Criteria}

1. All Patients who underwent Upper GI scopy for acid peptic disease were included.

2. Patients between 18 to 65 years were included.

\section{Exclusion Criteria}

1. Patients with bleeding disorder.

2. Patients who were receiving anticoagulant therapy.

3. Patients who were diagnosed with Ca. stomach.

\section{RESULTS}

In this study, out of 250 (182 male, 68 female) patients who underwent upper GI scopy, it was observed that out of 250 cases, 101 patients (72 males and 29 females) had peptic ulcers. Out of 101 cases, $73(72.27 \%)$ patients (52 males and 21 females) was positive and $28(27.72 \%)$ were negative $(20$ male and 8 female) for $H$. pylori infection on rapid urease 
test. In this study we observe that incidence rate of $\mathrm{H}$. pylori infection rate in general population between age of 18 to 65 was $40.4 \%$. There was no significant association of $\mathrm{H}$. pylori infection in relation to gender $(\mathrm{P}=0.984)$.

Eradication therapy given for 14 days to all 73 positive patients. After completion of eradication therapy, repeat endoscopy was done after 4 weeks and found that out of 73 positive cases, $65(89.041 \%)$ patients who were kept on maintenance dose of PPI for 3 weeks were cured. Those 8 patients who were not cured were allowed to continue eradication therapy for 14 more days and then on PPI for 3 weeks. After completion of this treatment, they were found negative for $\mathrm{H}$. pylori infection on repeat endoscopy. So in this study, we observe that there was high response rate for eradication therapy with good compliance. It was also noted that after completion of eradication therapy followed by maintenance therapy, there was no recurrence in any patient ( $0 \%$ recurrence rate).

\begin{tabular}{|c|c|c|c|}
\hline H. pylori infection & Male & Female & Total \\
\hline Positive & 52 & 21 & 73 \\
\hline Negative & 20 & 8 & 28 \\
\hline Total & $\mathbf{7 2}$ & $\mathbf{2 9}$ & $\mathbf{1 0 1}$ \\
\hline Table 1. Total Cases (101) Containing Peptic Ulcers \\
\hline
\end{tabular}

\begin{tabular}{|c|c|c|}
\hline Eradication & $\mathbf{7 3}$ & $\mathbf{\%}$ \\
\hline Cured & 65 & $89.04 \%$ \\
\hline Not cured & 8 & $10.95 \%$ \\
\hline Table 2. Eradication Therapy for H. pylori Infection \\
\hline
\end{tabular}

Those 8 patients who were not cured were allowed to continue eradication therapy for 14 more days and then on PPI for 3 weeks. After completion of this treatment, they were found negative for $\mathrm{H}$. pylori infection on repeat endoscopy.

\begin{tabular}{|c|c|c|c|c|c|c|c|}
\hline $\begin{array}{c}\text { Forrest } \\
\text { Classification }\end{array}$ & Ia & Ib & IIa & IIb & IIc & III & Total \\
\hline No. of Cases & 3 & 4 & 2 & 10 & 30 & 52 & 101 \\
\hline Table 3. Forrest Classification of Cases: According to \\
Forrest Classification Patients were Categorised as \\
Follows
\end{tabular}

\section{DISCUSSION}

In this study, those patients who were having signs and symptoms of peptic ulcer and who underwent upper GI endoscopy were selected. Symptoms may range from vague abdominal pain, epigastric pain and burning sensation, dyspepsia, even history of haematemesis. First plan of treatment is medical line of management. For those who were positive for $\mathrm{H}$. pylori, initial eradication therapy followed by antacids (PPI) is the best line of treatment. According to Forrest classification, we had Forrest Ia- 3, Ib-4 cases, IIa-2, IIb-10, IIc-30, III-52 cases, all are managed conservatively. For eradication, we used Omeprazole $20 \mathrm{mg}$ BID + Amoxicillin $500 \mathrm{mg}$ BID and Metronidazole $400 \mathrm{mg}$ BID.

In this study, it was observed that out of 101; 73 (72.27\%) patients were positive. Eradication therapy was given for 14 days to all 73 positive patients. After completion of eradication therapy, repeat endoscopy was done after 4 weeks and found that out of 73 positive cases, 65 (89.04\%) patients were cured. Those 8 patients which were not cured were allowed to continue eradication therapy for 14 more days and then on PPI for 3 weeks. After completion of this treatment, they were found negative for $\mathrm{H}$. pylori infection on repeat endoscopy. Twenty three cases which were not associated with $\mathrm{H}$. pylori infection were managed with PPI for 3 weeks. In these, some patients who were not cured with PPI were started for eradication therapy who were then cured after completion of therapy.

There was no recurrence noted in all patients following consecutive upper GI scopy after 3 months of primary treatment $(0 \%$ recurrence rate).

\section{CONCLUSION}

Acid peptic disease is one of the most common condition encountered in routine practice. Majority of cases can be managed with medical treatment. Surgical treatment is needed for those who present with complications like intractable pain, massive upper GI bleeding, ulcer perforation, etc. For those who were positive for H. Pylori, eradication therapy (Omeprazole/Pantoprazole, Amoxicillin/Clarithromycin, Metronidazole/Ornidazole) with or without Bismuth subcitrate is the best treatment. Even those who were negative initially showed good response for eradication therapy. Early diagnosis using endoscopic management of peptic ulcer will definitely improve quality of life and help to prevent complications of ulcer like bleeding, perforation, intractable pain. Hence, early diagnosis and management using eradication therapy helps in reducing morbidity and mortality as compared to those who present late with complications.

\section{REFERENCES}

[1] Shah H, Shah $P$, Jarag $M$, et al. Prevention of helicobacter pylori infection in gastric and duodenal lesion as diagnosis by endoscopic biopsy. International Journal of Medical Science and Public Health 2016;5(1):93-6.

[2] Sharma M, Mehra P, Vohra P. Incidence of helicobacter pylori in patients with gastroduodenal disorders. Innovative Journal of Medical and Health Science 2013;3(1):10-5.

[3] Rangaswamy P, Rubby SA. A clinical study of prevalence of helicobacter pylori in patients with gastritis. Int Surg J 2016;3(4):1979-82.

[4] Vu C, Ng YY. Prevention of helicobacter pylori in peptic ulcer disease in a Singapore hospital. Singapore Med J 2000;41(10):478-81.

[5] Berry V, Sagar V. Rapid urease test to diagnose helicobacter pylori infection. JK Science 2006;8(2):868.

[6] van Keeken N, van Hattum E, de Boer WA. Validation of a new, commercially available dry rapid urease test for the diagnosis of Helicobacter pylori infection in gastric biopsies. Neth J Med 2006;64(9):329-33.

[7] Katelaris PH, Forbes GM, Talley NJ, et al. A randomized comparison of quadruple and triple therapies for Helicobacter pylori eradication: the QUADRATE study. Gastroenterology 2002;123(6):1763-9.

[8] Kim JS, Park SM, Kim B. Endoscopic management of peptic ulcer bleeding. Clin Endosc 2015;48(2):106-11. 